This is the pre-peer reviewed version of the following article: M. Diab, K. Shreteh, N. Afik, M. Volokh, S. Abramovich, U. Abdu, T. Mokari, Adv. Sustain. Syst. 2018, 2, 1800001, which has been published in final form at DOI: 10.1002/adsu.201800001. This article may be used for non-commercial purposes in accordance with Wiley Terms and Conditions for Use of SelfArchived Versions

\title{
Design of Hierarchal 3D Metal Oxide Structures for Water Oxidation and Purification
}

Mahmud Diab, Karam Shreteh, Noa Afik, Michael Volokh, Sigal Abramovich, Uri Abdu and Taleb Mokari*

Dr. Mahmud Diab, Karam Shreteh, Noa Afik, Dr. Michael Volokh, and Prof. Taleb Mokari Department of Chemistry, Ben-Gurion University of the Negev, 8410501, Israel

E-mail: mokari@bgu.ac.il

Prof. Sigal Abramovich

Department of Geological \& Environmental Sciences, Ben-Gurion University of the Negev, 8410501, Israel

Prof. Uri Abdu

Department of Life Sciences, Ben-Gurion University of the Negev, 8410501, Israel

Keywords: Foraminifera; inorganic nanomaterials; porous 3D structures; scaffolds; water oxidation and purification.

\begin{abstract}
Given their unique properties, tremendous progress has been realized in the use of nanostructured materials for various applications. However, their incorporation and fabrication into prototypic devices remain challenging due to their limited ability to form hierarchical three-dimensional (3D) structures through the use of large scale, low cost, and facile processes. Herein, we address this challenge and demonstrate the growth of unique hierarchical structures by coating calcareous foraminiferal shells with metal oxide materials via simple and inexpensive processes conducted on a large scale. Foraminifera are highly diverse and abundant marine unicellular protists surrounded by large, ranging from $0.1 \mathrm{~mm}$ to more than $200 \mathrm{~mm}$ in size, identical porous and complex hierarchical shells. In the present study, these hierarchal structures were investigated in electrochemical water oxidation reactions and tested in terms of their ability to purify water from inorganic (metal ions) contaminates. The remarkable performances of the prototype filters and catalysts developed here, among the best recorded values in both fields, are reported. These findings thus open new perspectives for catalytic and water purification applications.
\end{abstract}




\section{Body of communication}

Hierarchical 3-dimensional (3D) nanostructures are widely recognized and during the past two decades, this field has witnessed a rapid rise in interest due to the unique properties of such structures. Still, a persistent need for such materials remains. Indeed, the limited success realized in forming hierarchical structures of inorganic materials (HSIMs) is one of the major obstacles preventing technological progress in various applications involving such moieties, such as catalysis, capacitors, battery, purification technology, and electronics. Major efforts for fabricating well-defined 3D structures have primarily focused on four different routes, namely photo/electro lithography, assembly, 3D printing, and template-mediated methods, with various structures having been obtained through those techniques at high quality/yield. ${ }^{[1]}$ However, these methods suffer from high costs, difficulty in fabricating free-standing structures and, in some cases, limited throughput. ${ }^{[2,3]}$ On the other hand, templated approaches are usually facile, relatively inexpensive, and are able to produce complex structures. In considering templates, several fascinating microorganisms display highly ordered and complex structures, such as viruses, bacteria, fungi, diatoms, and foraminifera that cannot be easily mimicked artificially. ${ }^{[4,5]}$ Relative to synthetic materials, hardened biological materials offer clear advantages, given the ability of living organisms to engineer and fabricate materials with structures and dimensions that are very challenging to achieve in traditional methods, thereby offering a wide spectrum of applied possibilities. Furthermore, such organisms accurately replicate their structures and functionalities during evolution, which is crucial for their survival. These properties overcome issues related to the reproducibility of these identical and unique structures and can facilitate their use in high quality commercial products. Nevertheless, a clear disadvantage of using natural materials, especially those comprising a single component is that they usually suffer from poor inherent properties and, therefore, post-treatment processes are required to attain multi-functionalities. Thus, the combination of the natural template and introduced synthetic capabilities can be used to rationally create 3D structures with increased functionalities.

To date, extensive research on the use of microorganism shells as templates for forming various 3D morphologies for different applications has been reported. ${ }^{[3,6,7,8]}$ Several approaches describing the deposition/growth of nanomaterials on such templates, such as gas phase hydrothermal reactions, photoreduction, sonochemical processes, sputtering, and others have been described. ${ }^{[9,10,11]}$ The Mann group was able to form inorganic nanotubes (FeO, CdS, and $\mathrm{PbS}$ ) with deposition of metallic nanoparticles (such as $\mathrm{Pt}, \mathrm{Ag}$, and $\mathrm{Au}$ ) using the tobacco mosaic virus (TMV) as template. ${ }^{[11,12]}$ Kern and co-workers expanded the use of TMV for the 
formation of $\mathrm{Ni}$ and Co nanowires. ${ }^{[13]}$ Saraf and colleagues fabricated electrical conducting $\mathrm{Au}$ bridges of using the bacteria Bacillus cereus as template. ${ }^{[14]}$ Mirkin and co-workers produced a hierarchical structure of $\mathrm{Au}$ nanoparticles using fungal templates. ${ }^{[15]}$ In recent decades, substantial efforts have been invested in fabricating a well-defined 3D structures using diatom templates. ${ }^{[16,17,18,19,20,21]}$ For example, Haigh and associates formed a $\mathrm{MoS}_{2}$ layer using the diatom Coscinodiscus as template. ${ }^{[22]}$ Lang et al. expanded the potential application of diatoms by modifying their surface with $\mathrm{TiO}_{2}$ nanoparticles, and examined the photocatalytic performance. $^{[23]}$

One interesting group of microorganisms that present a variety of highly porous 3D shell structures is the foraminifera which are vastly diverse and abundant unicellular marine protists, found in all parts of the oceans, from the poles to the equator and from shallow intertidal regions to the deep sea. They formed amongst the most ancient and abundant fossils and their shells (the majority of which is made of calcium carbonate) accumulate in mass quantities in oceanic sediments, thus becoming one of the most important components of sedimentary (carbonate) rocks. ${ }^{[24,25,26]}$ Annual global production of calcium carbonate by foraminifera was estimated as 43 million tons, an amount representing close to $50 \%$ of the total annual $\mathrm{CaCO}_{3}$ precipitation in the ocean.

Despite their protist origin, foraminifera are relatively large in size (from 0.1 to more than $200 \mathrm{~mm}$ ) and are highly complex organisms. One of the most unique characteristics of foraminifera is their ability to build highly mesoporous 3D shells of $\mathrm{CaCO}_{3}$ of various shapes and sizes presenting complex internal and external structures. Surprisingly, despite their unique structures, these structures have not yet been used as templates for growing inorganic materials. In the present study, we harnessed the naturally designed morphologies of calcareous foraminiferal shells (CFS) to rationally form hierarchical structures of nanofeatures. We demonstrate the inexpensive and abundant formation of unique inorganic 3D porous structures using CFS of the benthonic genus Sorites as scaffolds. We subsequently examined their performance as an electrocatalyst for water oxidation and as a filter of inorganic containments.

A general and simple approach was developed for the growth of unique hierarchical 3D porous structures which offer metal and metal oxide nanofeatures using CFSs, as portrayed in Figure 1. The procedure for growing nanostructures on Sorites involved partial removal of the outer $\mathrm{CaCO}_{3}$ shell by transferring the organisms to a solution of $0.05 \mathrm{M} \mathrm{HCl}$ for 2-3 min and then washing with water (Figure S1). The removal of the outer layers of the shell allows for the grown materials to reach its interior walls and tunnels. Then, the Sorites were placed in different growth solutions for coating with inorganic materials as described in the Experimental 
section. Figure 1 presents optical and SEM images of Sorites coated with Co (A, E), MnO (B, $\mathrm{F}), \alpha-\mathrm{Fe}_{2} \mathrm{O}_{3}(\mathrm{C}, \mathrm{G})$, and $\mathrm{NiO}(\mathrm{D}, \mathrm{H})$. The conformal coating of the Sorites with different materials enabled for controlling the thickness of the coated materials from a few nanometers to a few micrometers as presented in the high magnification SEM images shown in the insets of Figure 1E, F, G, and $\mathrm{H}$.

The homogeneity of the coating in all samples was confirmed by EDX mapping and XRD characterization, as presented in Figure 1I, J, K and L. All of the coated materials were crystalline and clear peaks of rhombohedral $\mathrm{Mg}_{0.1} \mathrm{Ca}_{0.9} \mathrm{CO}_{3}$ and the coating materials $(\mathrm{Co}, \alpha-$ $\mathrm{Fe}_{2} \mathrm{O}_{3}, \mathrm{MnO}$, and $\mathrm{NiO}$ ) matched the fcc bulk structure. Formation of a new phase of rhombohedral $\mathrm{CaCO}_{3}$ was observed as a result of the heating process. The EDX data collected from all samples revealed that conformal coating had been achieved, as presented in the inset of the XRD patterns in Figure 1.

One of the most appealing advantages of using CFSs as scaffolds to grow various materials is the simplicity of sacrificially removing the scaffold while retaining the morphology. We tested the process of removing the Sorites template after its coating by a thick layer of a Co shell. The removal of the template was carried out by first annealing the samples and converting the $\mathrm{Co}$ into $\mathrm{Co}_{3} \mathrm{O}_{4}$ to provide additional stability and then immersing the Sorites@ $\mathrm{Co}_{3} \mathrm{O}_{4}$ sample in $\mathrm{HCl}$ solution $(0.1 \mathrm{M})$ for 20 minutes, followed by washing with distilled water. Figure 2 shows the process of etching the calcite template coated with $\mathrm{Co}_{3} \mathrm{O}_{4}$ material before (Figure 1A) and after (Figure 2A) calcite removal. Removal of the template was confirmed by XRD, which shows that the calcite peaks disappeared after etching and that only $\mathrm{Co}_{3} \mathrm{O}_{4}$ peaks could be detected, as shown in Figure 2B (bottom pattern). Figures $2 \mathrm{C}$ and 2D present SEM images of a cross-section of samples before and after the etching process, respectively, confirming how the hierarchical structure of the sample was preserved after removing the template. The removal of calcite from the sample was verified by EDX mapping. Before etching, the $\mathrm{Ca}$ (red) and $\mathrm{Co}$ (blue) signals are clearly shown in Figure $2 \mathrm{E}$, however, after etching, the $\mathrm{Ca}$ signal disappeared and only the Co signal was detected, as presented in Figure $2 \mathrm{~F}$. This etching process can be easily expanded to other inorganic materials that are stable in mild acidic solution.

One of the great motivations for designing materials in a hierarchical 3D structure configuration is the desire to achieve high surface area. Calculating the surface area of native Sorites (after removing the top layer) using the Brunauer-Emmett-Teller (BET) theory yields a value of $\sim 5 \mathrm{~m}^{2} / \mathrm{g}$. This value is comparable to the surface area reported for other biological 
scaffolds in use $\left(1.4-51 \mathrm{~m}^{2} / \mathrm{g}\right) .^{[28,29,30,31,32,33,34]}$ Coating Sorites with Co followed by etching of the template doubled the surface area of the structures $\left(\sim 8 \mathrm{~m}^{2} / \mathrm{g}\right)$.

This high surface area, combined with a hierarchical 3D arrangement, pave the way for the use of Sorites in several applications. Here, we focused on the potential of the HSIMs formed in two applications, namely water purification (i.e., removing metal cations) and catalysis (i.e., water oxidation). For both applications, a general requirement is a material with large surface area, an essential factor for creating highly efficient devices. HSIMs possess welldefined traits that make them ideal candidates as catalysts and filters, with the most significant being their high surface area, the accessibility of the reactants/monomers to reach the interior surface of the 3D structures, and that they provide a confined space (nano-reactor) for catalysis that can consequently lead to higher chemical yield/conversion. Finally, various inorganic materials can be grown that offer diverse functionalities.

To study the activity of the HSIMs in removing contaminates from water and in water oxidation catalysis, Sorites were coated with abundant inexpensive and non-toxic inorganic materials. In addressing the electrocatalytic properties of the HSIMs, Sorites@Co and Sorites@NiO were considered as electrocatalysts. Figure 3 presents a photograph of the electrodes (Figure 3A) and the electrochemical performance (Figure 3B) of the hierarchal structure coated with $\mathrm{Co}$ or NiO. The electrodes prepared from Sorites@Co (red) or Sorites@NiO (blue) showed maximal currents of $154 \mathrm{~mA} / \mathrm{cm}^{2}\left(62 \mathrm{~mA} / \mathrm{cm}^{2}\right)$ and $74 \mathrm{~mA} / \mathrm{cm}^{2}$ $\left(35 \mathrm{~mA} / \mathrm{cm}^{2}\right)$ at $1 \mathrm{~V}(0.8 \mathrm{~V})$ vs. $\mathrm{Ag} / \mathrm{AgCl}$ and an onset potential of $\sim 0.55 \mathrm{~V}$ vs. $\mathrm{Ag} / \mathrm{AgCl}$, respectively. A control experiment involving an electrode coated with silver paint generated a maximal current of $\sim 2 \mathrm{~mA} / \mathrm{cm}^{2}$ at $1 \mathrm{~V} v s$. $\mathrm{Ag} / \mathrm{AgCl}$ (Figure 3B, black). The reported current density is among the highest electrocatalytic currents obtained using cobalt- and nickel-based materials and the onset potential is comparable with the reported values using the same materials. ${ }^{[35,36,37,38,39,40,41,42]}$ Besides performance, the clear advantage of our electrocatalysts, as compared to the state-of-the-art electrocatalysts, is the simplicity in fabricating the anode, the low quantity of active materials ( $\mathrm{Co}, \mathrm{NiO}$, or others) needed to achieve high activities due to the formation of 3D structures and the direct costs of the process, which are considerably lower than needed to assemble most cobalt- and nickel-based electrocatalysts.

As the demand for clean water is steeply increasing, developing new structures that can remove metal ions have become more pronounced. With this in mind, we tested whether the HSIMs developed here can be used for removing metal cations (i.e., heavy and non-heavy metal ions) from contaminated water. We first examined the ability of untreated Sorites and Sorites that had been coated with inorganic layers to remove metal cations from water, as 
portrayed in Figure 4. ${ }^{[43,44]}$ Figure 4A shows an image of the filter and a schematic illustration of the filtration process. The performance of the filter was examined by passing three different contaminated solutions of dissolved $\mathrm{Pb}(\mathrm{ac})_{2} \cdot 3 \mathrm{H}_{2} \mathrm{O}, \mathrm{CdCl}_{2}$, or $\mathrm{CuCl}_{2}$, in water through $2 \mathrm{~g}$ of active material corresponding to untreated Sorites or Sorites@inorganic materials in a cylindrical tube. The filtration process was carried out without external pressure. This is a clear advantage, as compared to many commercial filters.

The concentration of metal cations, before and after filtration, was measured by atomic absorption spectroscopy (AAS). Surprisingly, untreated Sorites structures, with no surface modification, exhibited remarkable performance. Figure $4 \mathrm{C}$ shows that the concentrations of the three cation solutions, before and after the filtration, were reduced significantly. Ten $\mathrm{mL}$ of metal solutions containing $136 \mathrm{ppm}$ of $\mathrm{Pb}^{2+}$ (Figure 4C, black), $103 \mathrm{ppm}$ of $\mathrm{Cd}^{2+}$ (Figure 4C, orange) or $108 \mathrm{ppm}$ of $\mathrm{Cu}^{2+}$ (Figure 4C, pink), were passed through the untreated Sorites. The concentrations of the metal cations, after filtration, were reduced to $<0.02 \mathrm{ppm}, 2.7 \mathrm{ppm}$, and $6.3 \mathrm{ppm}$ of $\mathrm{Pb}^{2+}, \mathrm{Cd}^{2+}$, and $\mathrm{Cu}^{+2}$, respectively.

To improve filter performance, we coated the Sorites with iron hydroxide (Figure 4B). Iron-based oxides are promising candidate materials for extraction of metal ions from water/wastewater. ${ }^{[45,46,47,48]}$ Iron hydroxide is a particularly interesting material for removing ions due to the high affinity of its hydroxide groups for metal cations $\left(=\mathrm{FeOH}+\mathrm{M}^{2+} \rightleftharpoons\right.$ $\left.\equiv \mathrm{FeOM}^{+}+\mathrm{H}^{+}\right) .{ }^{[49]}$ Moreover, iron hydroxide is non-toxic, abundant, inexpensive, and easy to grow (see Experimental section).

When Sorites@ $\mathrm{Fe}(\mathrm{OH})_{x}$ were used instead of untreated Sorites, the purification efficiency was noticeably improved, specifically for $\mathrm{Cd}^{2+}$ and $\mathrm{Cu}^{2+}$ (using the same initial concentrations of cations that were used in the experiments with untreated Sorites). Similar to untreated Sorites, the use of Sorites@ $\mathrm{Fe}(\mathrm{OH})_{x}$ led to a significant decrease in lead concentration following filtration, with levels dropping from $136 \mathrm{ppm}$ to $<0.02 \mathrm{ppm}$ (below the detection limit of the instrument), corresponding to the removal of $99.98 \%$ of the lead contaminate (Figure 4C, black). Regarding $\mathrm{Cd}^{2+}$, the AAS measurements showed a reduction from $103 \mathrm{ppm}$ to $0.08 \mathrm{ppm}$ after filtration, corresponding to a purification of $>99.9 \%$ of the cation (Figure 4C, orange). A significant improvement was also recorded for $\mathrm{Cu}^{2+}$, with the concentration being reduced $99.99 \%$ from $108 \mathrm{ppm}$ to $<0.005 \mathrm{ppm}$, as shown in Figure $4 \mathrm{C}$ (pink).

In summary, we have shown that the design of hierarchical 3D metal oxide structures can be achieved using calcareous foraminiferal shells as scaffolds. Furthermore, the ability to tailor the chemical composition, uniformity and thickness of the metal oxide shell via thermal 
decomposition approach of single source precursors was accomplished. The SEM, EDX and XRD analyses confirm that the hierarchical 3D cobalt structures were preserved after removing the template by etching the calcite under mild acidic conditions. Remarkable performances of the Sorites@Co and Sorites@NiO catalysts, in electrochemical water oxidation reactions, and Sorites@ $\mathrm{Fe}(\mathrm{OH})_{x}$ filter, in water purification processes, were achieved. The use of the identical and 3D porous structures of fossil scaffolds, corresponding to an abundant and inexpensive source, combined with facile, general, and low-cost coating process using numerous inorganic and organic materials can pave the way for the development of next-generation versatile catalysts, filters, batteries, photonic crystals, etc.

\section{Experimental Section}

Materials: $\mathrm{Co}(\mathrm{ac})_{2}(99.995 \%)$ and $\mathrm{Fe}(\mathrm{ac})_{2}$ (99.995) were purchased from Sigma Aldrich. $\mathrm{Mn}(\mathrm{ac})_{2}(98 \%)$ and $\mathrm{Ni}(\mathrm{ac})_{2} \cdot 4 \mathrm{H}_{2} \mathrm{O}(>98 \%)$ were purchased from Strem. $\mathrm{FeSO}_{4} \cdot 7 \mathrm{H}_{2} \mathrm{O}(99 \%)$, hexadecylamine (HDA, 90\%), and $\mathrm{NaOH}(98 \%)$ were purchased from Alfa Aesar.

Sorites pre-treatment: Sorites were immersed in $0.05 \mathrm{M} \mathrm{HCl}$ solution for 2-3 min at room temperature to clean and etch their outermost layer.

Coating with metal oxide nanostructure: Forty $\mathrm{mg}$ of $\mathrm{M}(\mathrm{ac})_{2}(\mathrm{M}: \mathrm{Co}, \mathrm{Ni}, \mathrm{Fe}, \mathrm{Mn}$ ) were dissolved in $1 \mathrm{~mL}$ HDA. Then, a $20 \mathrm{~mL}$ vial which containing the Sorites $(10 \mathrm{mg})$ and $500 \mu \mathrm{L}$ of the metal acetate solution was placed on a heating plate inside a glove box and heated at $270{ }^{\circ} \mathrm{C}$ for $20 \mathrm{~min}$, except in the case of cobalt, which was heated at $300{ }^{\circ} \mathrm{C}$ for $30 \mathrm{~min}$. The products were cleaned by hexane and dried at $60{ }^{\circ} \mathrm{C}$.

Coating with $\mathrm{Fe}(\mathrm{OH})_{x}$ : Ten $\mathrm{mL}$ of $0.1 \mathrm{M}$ iron salt $\left(\mathrm{FeSO}_{4} \cdot 7 \mathrm{H}_{2} \mathrm{O}, \mathrm{pH}=3\right)$ were added into vial containing $0.5 \mathrm{~g}$ Sorites. The iron solution was removed after $30 \mathrm{~min}$, and the Sorites with the adsorbed iron salt were heated at $90{ }^{\circ} \mathrm{C}$.

Etching process: Sorites that were coated with cobalt nanostructures were heated at $550{ }^{\circ} \mathrm{C}$ for $5 \mathrm{~h}$ to convert $\mathrm{Co}$ metal to $\mathrm{Co}_{3} \mathrm{O}_{4}$. Then, the cobalt oxide structures were transferred to $0.1 \mathrm{M}$ $\mathrm{HCl}$ solution for $30 \mathrm{~min}$ for complete etching of the Sorites $\mathrm{CaCO}_{3}$.

Working electrode preparation and electrochemical measurements: Electrocatalytic measurement of the Sorites@Co and Sorites@NiO was carried out in a 1 M aqueous $\mathrm{NaOH}$ solution, using a VersaSTAT 3 potentiostat in a three-electrode system. The 3D structures acted as the working electrode, a platinum wire as the counter electrode, and $\mathrm{Ag} / \mathrm{AgCl}$ in saturated $\mathrm{KCl}$ served as the reference electrode, separated by glass frits. The voltage was swept between -0.2 and $+1 \mathrm{~V} v s . \mathrm{Ag} / \mathrm{AgCl}$ at a scan rate $20 \mathrm{mV} / \mathrm{s}$. Preparation of the working electrode was carried out by pasting the Sorites@Co and Sorites@NiO to copper electrode using silver paint. 
The area of the working electrodes was calculated based on the dimensions of the Sorites@ Co and Sorites@NiO measured from SEM images as depicted in Figures S2, S3 and Tables 1 and 2).

Atomic absorption spectroscopy (AAS) measurement: The metal concentrations were measured by atomic absorption spectroscopy using Perkin Elmer Analyst 400. The samples were filtered with $0.22 \mu \mathrm{m}$ syringe filter and measured by the AAS in triplicate. A calibration curve was performed using standard solutions before each measurement.

Instruments: SEM images were recoded using a JEOL SM-7400F ultra-high-resolution electron microscope with a cold-field emission-gun operated at $3.5 \mathrm{kV}$. EDX was detected using energy-dispersive X-ray (EDX) detector coupled with the SEM, operated at an accelerating voltage of $15 \mathrm{kV}$. Phase analysis of the samples was carried out using the $X$-ray diffraction (XRD) method. The data were collected on an Empyrean Powder Diffractometer (Panalytical) equipped with a position sensitive (PSD) $\mathrm{X}^{\prime}$ Celerator detector using $\mathrm{Cu} \mathrm{K} \alpha$ radiation $(\lambda=1.5418 \AA)$ and operated at $40 \mathrm{kV}$ and $30 \mathrm{~mA}$. UV-Vis absorbance measurements were taken using a Cary 5000 UV-Vis-NIR spectrophotometer.

\section{Acknowledgements}

This work was supported by funding from the European Research Council (ERC) under the European Union's Horizon 2020 research and innovation programme (grant agreement No 755301). We thank the Interuniversity Institute for Marine Sciences of Eilat, Israel for the logistic support of the field work. The authors thank Dr. Dmitry Mogilynaski for performing the XRD measurements. 


\section{References}

[1] J. Gao, Y. Liu, H. Xu, Z. Wang, X. Zhang, Langmuir 2009, 25, 4365.

[2] E. K. Payne, N. L. Rosi, C. Xue, C. A. Mirkin, Angew. Chem, Int. Ed. 2005, 44, 5064.

[3] S. Kinoshita, S. Yoshioka, K. Kawagoe, Proc. Biol. Sci. 2002, 269, 1417.

[4] P. F. Joanna Aizenberg, James C. Weaver, Monica S. Thanawala, Vikram C. Sundar, Daniel E. Morse, Science 2005, 309, 275.

[5] C. E. Hamm, R. Merkel, O. Springer, P. Jurkojc, C. Maier, K. Prechtel, V. Smetacek, Nature 2003, 421, 841.

[6] X. Gao, L. Jiang, Nature 2004, 432, 36.

[7] Y. Li, J. Zhang, S. Zhu, H. Dong, Z. Wang, Z. Sun, J. Guo, B. Yang, J. Mater. Chem. 2009, 19, 1806.

[8] J. Huang, X. Wang, Z. L. Wang, Nano Lett. 2006, 6, 2325.

[9] H. Zhou, T. Fan, X. Li, J. Ding, D. Zhang, X. Li, Y. Gao, Eur. J. Inorg. Chem. 2009, 2009, 211.

[10] S. Shian, Y. Cai, M. R. Weatherspoon, S. M. Allan, K. H. Sandhage, J. Am. Ceram. Soc. 2006, 89, 694.

[11] E. Dujardin, C. Peet, G. Stubbs, J. N. Culver, S. Mann, Nano Lett. 2003, 3, 413.

[12] W. Shenton, S. Mann, T. Douglas, M. Young, G. Stubbs, Adv. Mater. 1999, 11, 253.

[13] M. Knez, A. M. Bittner, F. Boes, C. Wege, H. Jeske, E. Maiß, K. Kern, Nano Lett. 2003, 3, 1079.

[14] V. Berry, S. Rangaswamy, R. F. Saraf, Nano Lett. 2004, 4, 939.

[15] D. A. Nanoparticles, Z. Li, S. Chung, J. Nam, D. S. Ginger, C. A. Mirkin, Angew. Chem. Int. Ed. 2003, 115, 2408.

[16] N. L. Rosi, C. S. Thaxton, C. A. Mirkin, Angew. Chem. Int. Ed. 2004, 43, 5500.

[17] R. R. Unocic, F. M. Zalar, P. M. Sarosi, Y. Cai, K. H. Sandhage, Chem. Commun. 2004, 1, 796.

[18] F. Xu, Y. Wang, X. Wang, Y. Zhang, Y. Tang, P. Yang, Adv. Mater. 2003, 15, 1751.

[19] Y. Wang, Y. Tang, A. Dong, X. Wang, N. Ren, Z. Gao, J. Mater. Chem. 2002, 12, 1812.

[20] Y. J. Wang, Y. Tang, X. D. Wang, a. G. Dong, W. Shan, Z. Gao, Chem. Lett. 2001, 1118.

[21] M. W. Anderson, S. M. Holmes, N. Hanif, C. S. Cundy, Angew. Chem. Int. Ed. 2000, 39, 2707.

[22] E. A. Lewis, D. J. Lewis, A. A. Tedstone, G. Kime, S. Hammersley, P. Dawson, D. J. Binks, P. O'Brien, S. J. Haigh, Chem. Mater. 2016, 28, 5582.

[23] Y. Lang, F. del Monte, B. J. Rodriguez, P. Dockery, D. P. Finn, A. Pandit, Sci. Rep. 2013, 3, 3205.

[24] B. K. Sen Gupta, Mod. Foraminifera 2003, 36, 384.

[25] A. R. Loeblich, H. Tappan, Foraminiferal Genera and Their Classification, Springer US, Boston, MA, 1988.

[26] J. W. Murray, Ecology and Applications of Benthic Foraminifera, Cambridge University Press, 2006.

[27] O. F. Z. Khan, P. O’Brien, Polyhedron 1991, 10, 325.

[28] M. S. Aw, S. Simovic, Y. Yu, J. Addai-mensah, D. Losic, Powder Technol. 2012, 223, 52.

[29] Z. Bao, M. R. Weatherspoon, S. Shian, Y. Cai, P. D. Graham, S. M. Allan, G. Ahmad, M. B. Dickerson, B. C. Church, Z. Kang, H. W. Abernathy III, C. J. Summers, M. Liu, K. H. Sandhage, Nature 2007, 446, 172.

[30] J. Q. Dalagan, E. P. Enriquez, L.-J. Li, C.-T. Lin, Mater. Sci. 2013, 31, 226.

[31] X. L. Guo, M. Kuang, F. Li, X. Y. Liu, Y. X. Zhang, F. Dong, D. Losic, Electrochim. 
Acta 2016, 190, 159.

[32] A. Jantschke, C. Fischer, R. Hensel, H.-G. Braun, E. Brunner, Nanoscale 2014, 6, 11637.

[33] D. Losic, Y. Yu, M. S. Aw, S. Simovic, B. Thierry, J. Addai-Mensah, Chem. Commun. 2010, 46, 6323.

[34] Y. Yu, J. Addai-Mensah, D. Losic, Sci. Technol. Adv. Mater. 2012, 13, 15008.

[35] B. S. Yeo, A. T. Bell, J. Am. Chem. Soc. 2011, 133, 5587.

[36] Y. Zhao, S. Chen, B. Sun, D. Su, X. Huang, H. Liu, Y. Yan, K. Sun, G. Wang, Sci. Rep. 2015, 5, 7629.

[37] S. Mao, Z. Wen, T. Huang, Y. Hou, J. Chen, Energy Environ. Sci. 2014, 7, 609.

[38] P. W. Menezes, A. Indra, D. González-Flores, N. R. Sahraie, I. Zaharieva, M. Schwarze, P. Strasser, H. Dau, M. Driess, ACS Catal. 2015, 5, 2017.

[39] H. Tüysüz, Y. J. Hwang, S. B. Khan, A. M. Asiri, P. Yang, Nano Res. 2013, 6, 47.

[40] M. Gong, W. Zhou, M.-C. Tsai, J. Zhou, M. Guan, M.-C. Lin, B. Zhang, Y. Hu, D.-Y. Wang, J. Yang, S. J. Pennycook, B.-J. Hwang, H. Dai, Nat. Commun. 2014, 5, 4695.

[41] A. Singh, S. L. Y. Chang, R. K. Hocking, U. Bach, L. Spiccia, Energy Environ. Sci. 2013, 6, 579.

[42] K. Sun, F. H. Saadi, M. F. Lichterman, W. G. Hale, H.-P. Wang, X. Zhou, N. T. Plymale, S. T. Omelchenko, J.-H. He, K. M. Papadantonakis, B. S. Brunschwig, N. S. Lewis, Proc. Natl. Acad. Sci. 2015, 112, 201423034.

[43] R. Ahmad, R. Kumar, S. Haseeb, Arab. J. Chem. 2012, 5, 353.

[44] M. Pettinato, S. Chakraborty, H. A. Arafat, V. Calabro, Ecotoxicol. Environ. Saf. 2015, 121, 57.

[45] Y. Fan, F. Su, K. Li, C. Ke, Y. Yan, Sci. Rep. 2017, 7, 45643.

[46] C. Park, J. Jung, C. W. Lee, J. Cho, Sci. Rep. 2016, 6, 39136.

[47] P. N. Dave, L. V Chopda, J. Nanotechnol. 2014, 2014, 398569/1.

[48] M. Hua, S. Zhang, B. Pan, W. Zhang, L. Lv, Q. Zhang, J. Hazard. Mater. 2012, 211$212,317$.

[49] T. B. Scott, G. C. Allen, P. J. Heard, A. C. Lewis, D. F. Lee, Proc. R. Soc. A Math. Phys. Eng. Sci. 2005, 461, 1247. 


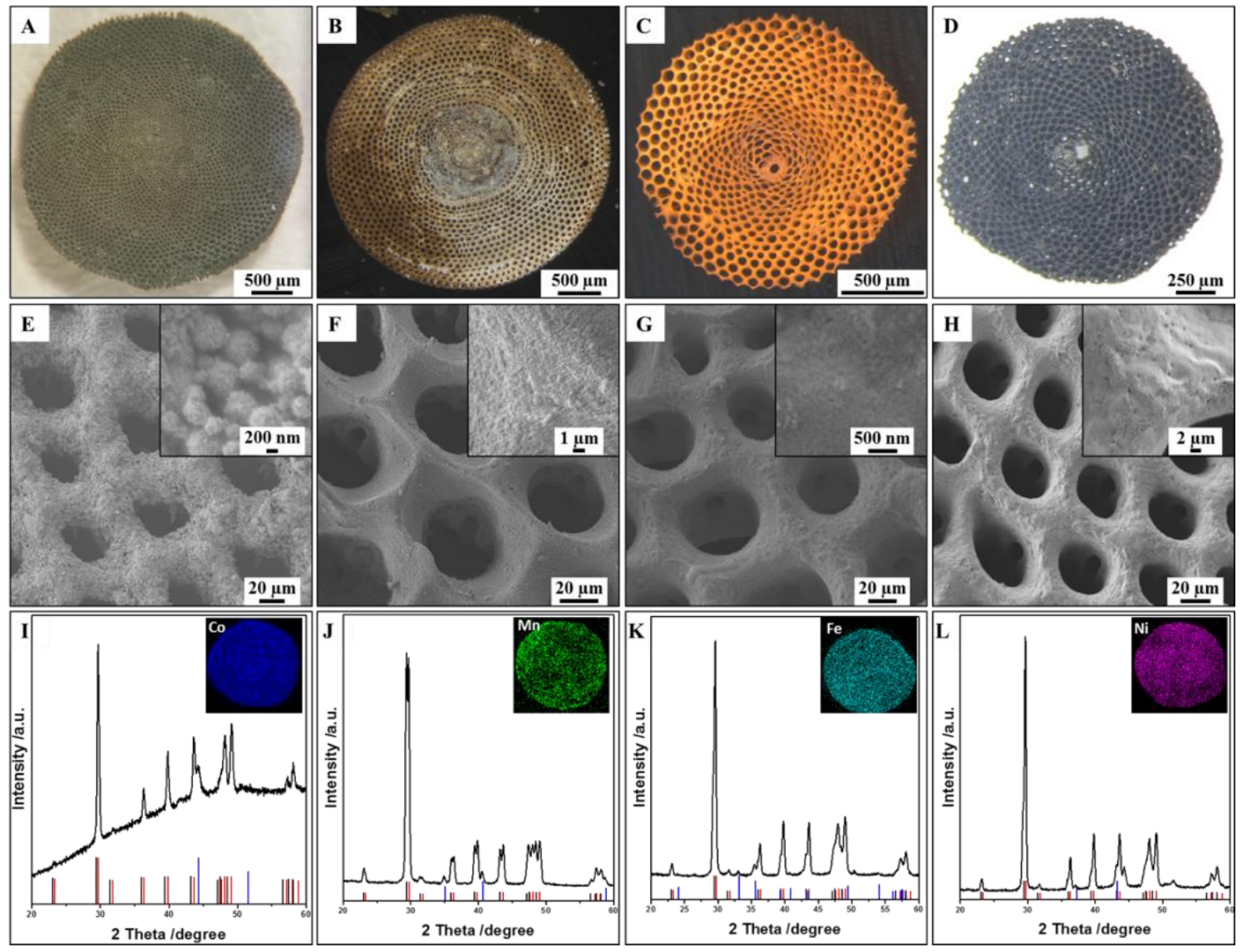

Figure 1. The generality of coating Sorites structures with different materials. A-D) Optical images and E-H) SEM images of the Sorites coated with $\mathrm{Co}, \mathrm{MnO}, \alpha-\mathrm{Fe}_{2} \mathrm{O}_{3}$, and $\mathrm{NiO}$, respectively. High magnification SEM image of each structure is shown in the inset. I-L) XRD patterns and EDX mapping (inset) of the Sorites coated with $\mathrm{Co}, \mathrm{MnO}, \alpha-\mathrm{Fe}_{2} \mathrm{O}_{3}$, and $\mathrm{NiO}$, respectively. The red, black, and blue lines in the XRD spectra correspond to the bulk structures of rhombohedral $\mathrm{Mg}_{0.1} \mathrm{Ca} 0.9 \mathrm{CO}_{3}$, rhombohedral $\mathrm{CaCO}_{3}$, and to the coated materials, respectively. 

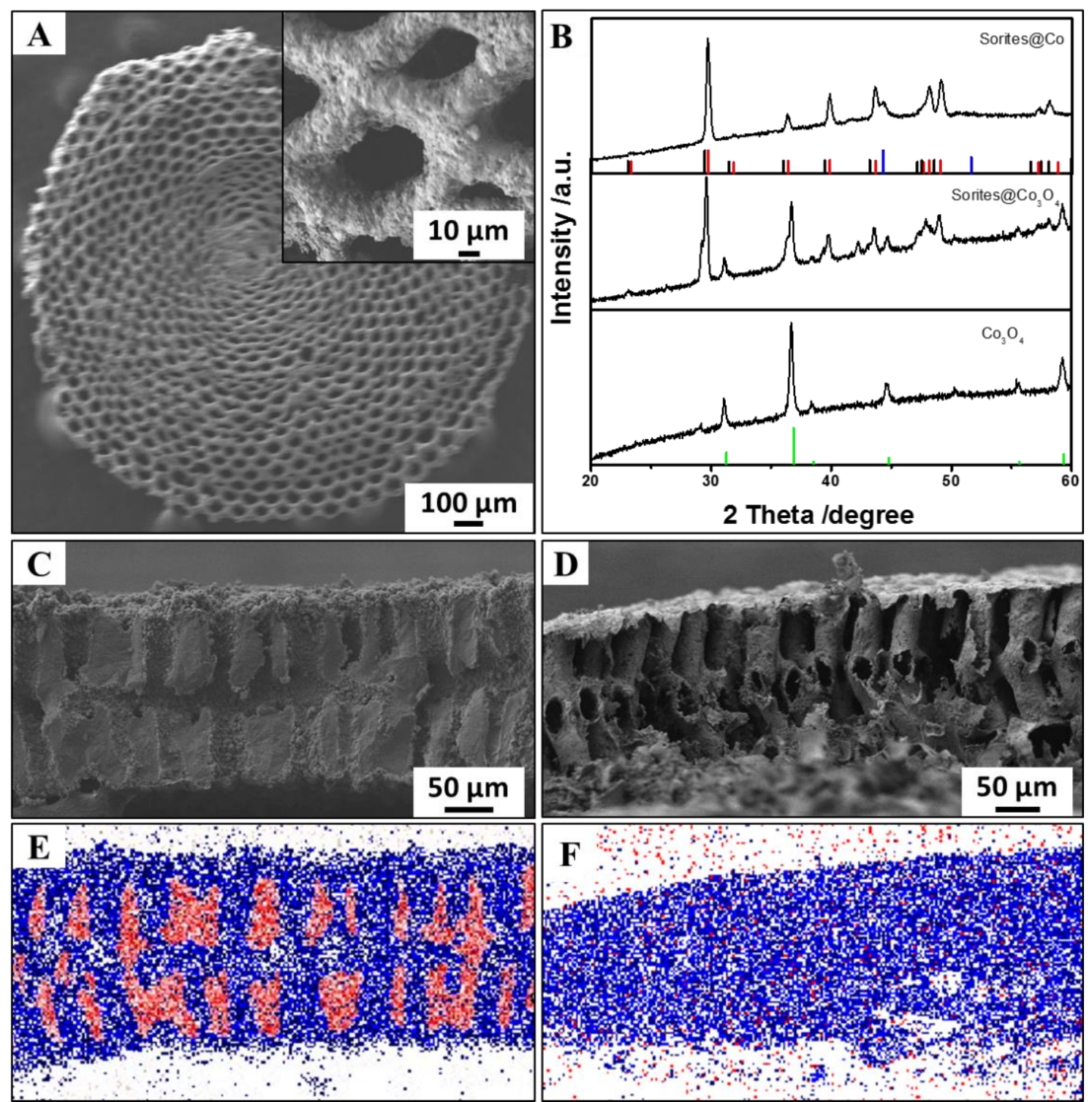

Figure 2. SEM images of the 3D structures before and after removing the $\mathrm{CaCO}_{3}$ template. A) SEM images of top view after etching the Sorites templates, B) XRD pattern of Sorites@Co (upper pattern), Sorites@ $\mathrm{Co}_{3} \mathrm{O}_{4}$ (middle pattern) and pure $\mathrm{Co}_{3} \mathrm{O}_{4}$ (bottom pattern). The red, black, blue, and green lines in the XRD spectra correspond to the bulk structures of rhombohedral $\mathrm{Mg}_{0.1} \mathrm{Ca} 0.9 \mathrm{CO}_{3}$, rhombohedral $\mathrm{CaCO}_{3}$, cubic $\mathrm{Co}$, and $\mathrm{Co}_{3} \mathrm{O}_{4}$, respectively. $(\mathrm{C}$ and D) SEM images of cross section view of the structures, (C) before etching and (D) after etching. EDX mapping of the images shown in (C and D) were taken, (D) before etching and (F) after etching the Sorites template. The $\mathrm{Ca}$ and $\mathrm{Co}$ are colored in red and blue, respectively. 

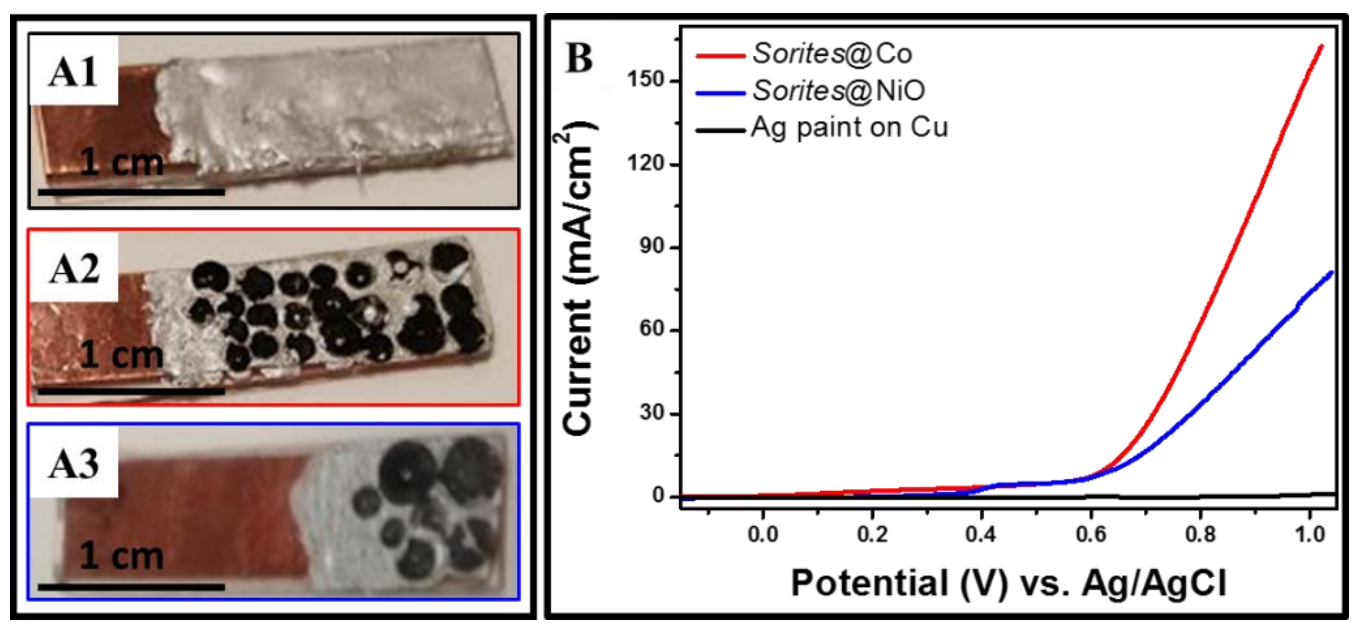

Figure 3. A) Photograph images of the prepared electrodes, on the top (A1) the silver paint, on the middle (A2) Sorites@Co, and on the bottom (A3) Sorites@NiO. A) J-V curve for water oxidation reaction using the Sorites@Co (red trace), Sorites@ NiO (blue trace), and silver paint (black trace) on $\mathrm{Cu}$ electrode, with a scan rate of $20 \mathrm{mV} / \mathrm{s}$.
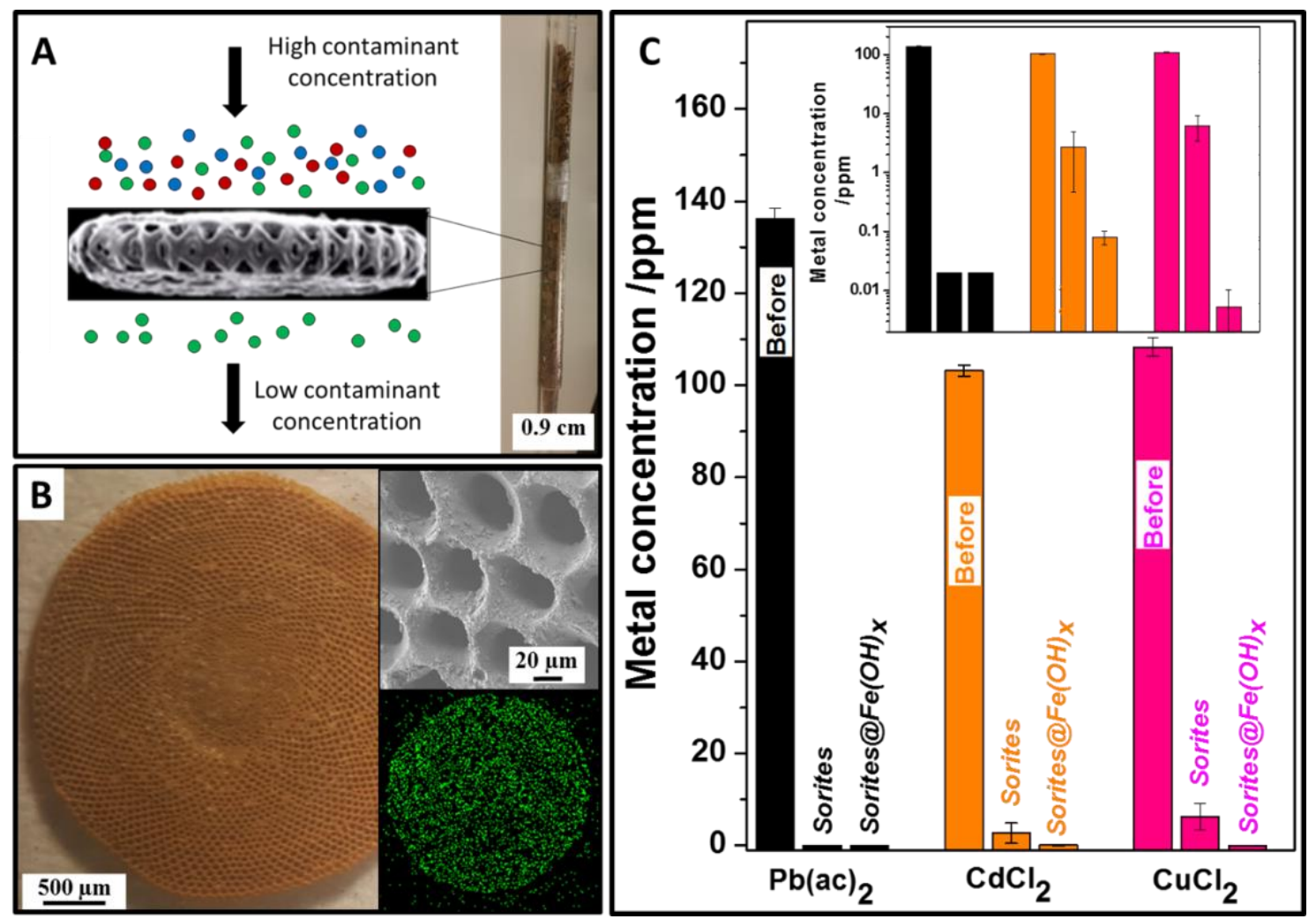

Figure 4. A) Optical image of the filter and a schematic description of the filtration process. B) Optical image of the Sorites@ $\mathrm{Fe}(\mathrm{OH})_{x}$ and high magnification SEM image and EDX mapping are shown in the insets. $\mathrm{C})$ Three different metal concentration $\left(\mathrm{Pb}^{2+}\right.$ black bars, $\mathrm{Cd}^{2+}$ orange bars, and $\mathrm{Cu}^{2+}$ pink bars) were filtered through plain Sorites and Sorites@ $\mathrm{Fe}(\mathrm{OH})_{x}$, where the solution concentration were checked before and after the filtration by AA. The insets in $\mathrm{C}$ show the concentration of the metal cations before and after filtration in a logarithmic scale. All error bars represent standard deviation from triplicate experiments. 